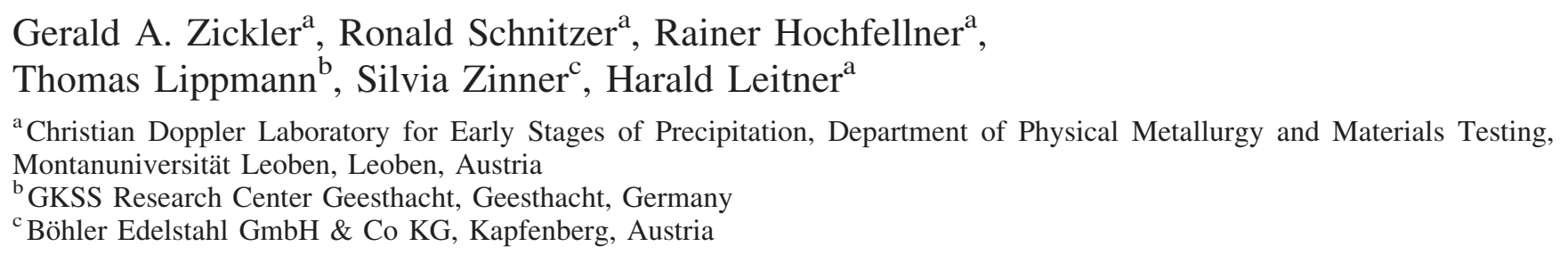

\title{
Transformation of reverted austenite in a maraging steel under external loading: an in-situ X-ray diffraction study using high-energy synchrotron radiation
}

Reverted austenite strongly influences the mechanical properties of maraging steels. Therefore, X-ray diffraction using high-energy synchrotron radiation was applied for in-situ studying of the reverse martensitic phase transformation under external load in a PH 13-8 Mo maraging steel. The volume fraction of austenite, the domain size of the crystallites, and the lattice parameters were determined as function of strain for differently aged samples. It is shown that the reverted austenite is not mechanically stable under external load. Scanning of the fractured sample along the axial direction shows that the volume fraction of the austenite and the domain sizes strongly depend on the distance from the point of fracture initiation.

Keywords: Maraging steel; Martensitic phase transformation; X-ray diffraction; Synchrotron radiation

\section{Introduction}

The deformation-induced martensitic transformation of metastable austenite in iron-nickel alloys was first discovered by Scheil [1] in 1932. In the past, numerous studies reported martensitic phase transformations in various austenitic stainless steels, especially focusing on low-carbon steels with the chemical composition $18 \mathrm{wt} . \%$ chromium and $10 \mathrm{wt} . \%$ nickel [2-14]. As often described in the literature, the martensitic transformation affects the plastic deformation behavior of these steels. This so-called effect of transformation-induced plasticity (TRIP effect) shows additional work-hardening and enhanced ductility arising from martensitic shear and plastic deformation processes around martensite plates $[4,14]$. Besides scientific interest, the TRIP effect is of great technological importance for industrial applications, such as automotive panels, since substantial enhancements of ductility, toughness, and deformability are achieved. Low-alloyed steels containing retained austenite also show the TRIP effect, which was reported by several studies [15-24]. Besides these two major classes of steels, austenitic stainless steels
( $\sim 18$ wt.\% Cr, $\sim 10$ wt.\% Ni) and low alloyed TRIP steels, not much is known about the deformation induced martensitic transformation behavior in other types of steels containing austenite, e.g. martensitic precipitation hardening steels (maraging steels). Maraging steels belong to the group of high strength steels possessing superior mechanical properties [25]. They have a martensitic matrix, which is strengthened by nanometer-sized intermetallic precipitates [25-28]. Maraging steels of type PH 13-8 Mo tend to form reverted austenite with increasing time of aging [26, $29,30]$. The volume fraction of the austenitic phase significantly influences the mechanical properties. Yield strength, tensile strength, and fatigue strength decrease, however, total elongation at fracture and absorbed energy in impact tests increase with increasing amount of austenite [31]. Katz et al. [32] studied the mechanical stability of austenite in high nickel and cobalt containing maraging steels. They reported that two different types of retained austenite can occur, which were mechanically stable or unstable at room temperature depending on the performed heat treatment [32]. However, the detailed deformation-induced kinetics of the martensitic phase transformations in maraging steels under external loads is still an open question and needs more detailed investigations.

Due to the fact that the amount of austenite in steels is of high scientific and technological relevance, the literature reports several experimental techniques for quantifying the austenitic phase in steels. Consecutively, the most important experimental methods are mentioned: transmission electron microscopy [5, 6, 22, 31], scanning electron microscopy applying electron backscattered diffraction [24], density measurements [7], Mössbauer absorption spectroscopy [32, 33], magnetic measurements $[1,2,7,8]$, dilatometer measurements [1, 23], atom probe tomography [33], differential scanning calorimetry [34], X-ray diffraction using laboratory sources $[1,9,10,12,15-17,23,24,31,32,35]$, and neutron diffraction [36]. Several studies compared the results of various methods, revealing advantages and disadvantages of the applied techniques. In particular, X-ray diffraction is commonly used because crystallographic phases, 
volume fractions, crystallite sizes, and lattice parameters can be detected quite easily. However, conventional diffractometers operating in Bragg-Brentano setup using laboratory sources bear the disadvantage of high photon absorption, which limits the investigated sample volume to a thin nearsurface zone with a thickness of the order of $10 \mu \mathrm{m}$, depending on the chemical composition. The high absorption makes $\mathrm{X}$-ray diffraction measurements extremely vulnerable to experimental artifacts due to surface texture and sample preparation. The use of synchrotron radiation overcomes these deficiencies and enables a superior potential of experimental studies. High-energy X-rays, such as provided by modern synchrotron radiation sources, bear the advantage of high photon brilliance and low absorption in most materials [37], enabling time-resolved in-situ measurements in transmission geometry of bulk materials of several millimeters in thickness $[38,39]$. In-situ X-ray diffraction experiments allow determination of the entire path of phase transformation on one single specimen. Therefore, influences from different chemical compositions and microstructures in various samples are avoided. Furthermore, in-situ studies enable the detection of phase transformations in elastically and plastically deformed samples. This procedure is of great importance for detecting the early stages of transformation. These facts make in-situ experiments superior to other ex-situ investigations using laboratory X-ray sources. Recently X-ray diffraction experiments using synchrotron radiation were applied for studying martensitic phase transformations in steels during in-situ heat treatments [38, 40-42] and external loading [18, 19, $43,44]$. In-situ tensile testing experiments were performed on fully austenitic steels [43, 44] and low-alloyed TRIP steels [18, 19]. However, phase transformations in maraging steels under external load have not been subject to in-situ $\mathrm{X}$-ray diffraction studies up to now.

The goal of the present study is a systematic investigation of the martensitic phase transformation behavior of reverted austenite in a maraging steel of the type PH 13-8 Mo under external load. A tensile testing machine was attached to a synchrotron radiation source representing a powerful tool to elucidate the phase transformation. The work focuses on the changes in volume fractions, crystallite sizes, and lattice parameters of differently heat treated material as a function of the applied strain. Therefore, it opens the field of a more detailed investigation on the martensitic transformation of reverted austenite in the widely used class of maraging steels.

\section{Experimental}

The material used for the present investigation was a commercial maraging steel of the type PH 13-8 Mo, which was supplied by Böhler Edelstahl GmbH \& Co KG, Kapfenberg, Austria, as a rolled bar with a diameter of $150 \mathrm{~mm}$. The nominal chemical composition of the steel is given in Table 1. All samples were solution annealed in air at a tem-

Table 1. Nominal chemical composition (wt.\%) of the maraging steel PH 13-8 Mo.

\begin{tabular}{|c|c|c|c|c|c|}
\hline $\mathrm{Fe}$ & $\mathrm{C}$ & $\mathrm{Cr}$ & $\mathrm{Mo}$ & $\mathrm{Ni}$ & $\mathrm{Al}$ \\
\hline base & 0.03 & 12.70 & 2.20 & 8.10 & 1.10 \\
\hline
\end{tabular}

Int. J. Mat. Res. (formerly Z. Metallkd.) 100 (2009) 11 perature of $1173 \mathrm{~K}$ for $1.5 \mathrm{~h}$ and then air-cooled to room temperature. Subsequently the samples were isothermally aged at $848 \mathrm{~K}$ for $3,5,10,15$, and $100 \mathrm{hrs}$ followed by aircooling to room temperature. The differently heat treated samples were machined to tensile test specimens according to the standard specifications of DIN EN 10002 with a diameter of $4 \mathrm{~mm}$ and a gauge length of $20 \mathrm{~mm}$. The longitudinal direction of the tensile test samples was parallel to the rolling direction of the raw material. The tensile testing was performed according to the standard DIN EN 10002 using a tensile testing machine Zwick UPM 1485 to characterize the influence of different heat treatments.

High-energy X-ray diffraction studies of the phase transformation in the investigated maraging steel were performed at the GKSS Engineering Materials Science Beamline HARWII-II [45] at HASYLAB/DESY. Figure 1 shows a schematic representation of the experimental setup used in the experiment. The synchrotron radiation was monochromatized by a water-cooled double-Laue-crystal (Si 111) to a nominal energy of $100 \mathrm{keV}$ and the beam cross section was defined by aperture slits to $0.5 \times 0.5 \mathrm{~mm}^{2}$ at the sample position. The X-ray diffraction experiments were performed in transmission geometry. A two-dimensional image plate detector (mar345) with a resolution of $3450 \times 3450$ pixels (pixel size: $100 \times 100 \mu^{2}$ ) was positioned at a sample-todetector distance of $950 \mathrm{~mm}$ to detect the scattered photons. For studying the phase transformations, a tensile testing machine (Instron 8800) was mounted on the sample tower of the diffractometer at the experimental station of the synchrotron beamline [45]. In-situ tensile testing was performed at room temperature according to the standard DIN EN 10002 up to fracture of the sample. However, for the $\mathrm{X}$-ray diffraction measurements the testing was stopped at constant cross-head displacement for several seconds. The position of measurement was at the zone of the lateral contraction, which was monitored by a calibrated video telescope. An exposure time of $10 \mathrm{~s}$ yielded diffraction patterns with sufficient counting statistics.

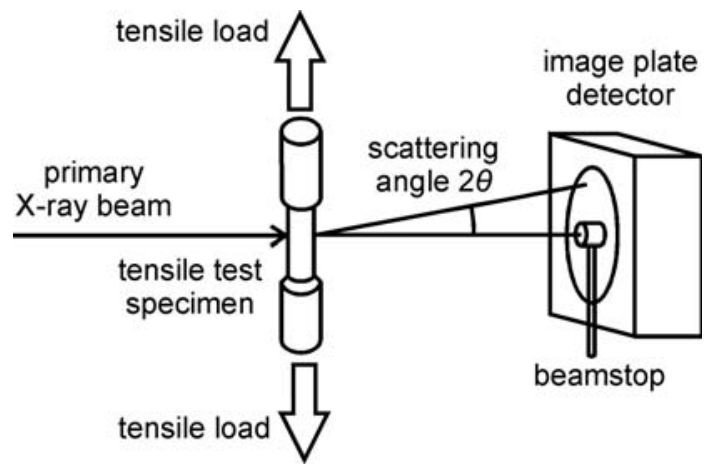

Fig. 1. Schematic representation of the experimental setup for the insitu tensile testing at the GKSS Materials Science Beamline HARWI-II at the Hamburger Synchrotronstrahlungslabor (HASYLAB)/Deutsches Elektronen-Synchrotron (DESY).

Figure 2 shows a typical two-dimensional X-ray diffraction pattern of the maraging steel PH 13-8 Mo isothermally aged at $848 \mathrm{~K}$ for $15 \mathrm{~h}$ in the unloaded state. All aged samples show Debye-Scherrer rings from the martensitic $\alpha^{\prime}$ phase and the austenitic $\gamma$ phase up to the $\alpha^{\prime}-400$ diffraction peak. However, the diffraction pattern of the solution treat- 
G. A. Zickler et al.: Transformation of reverted austenite in a maraging steel under external loading

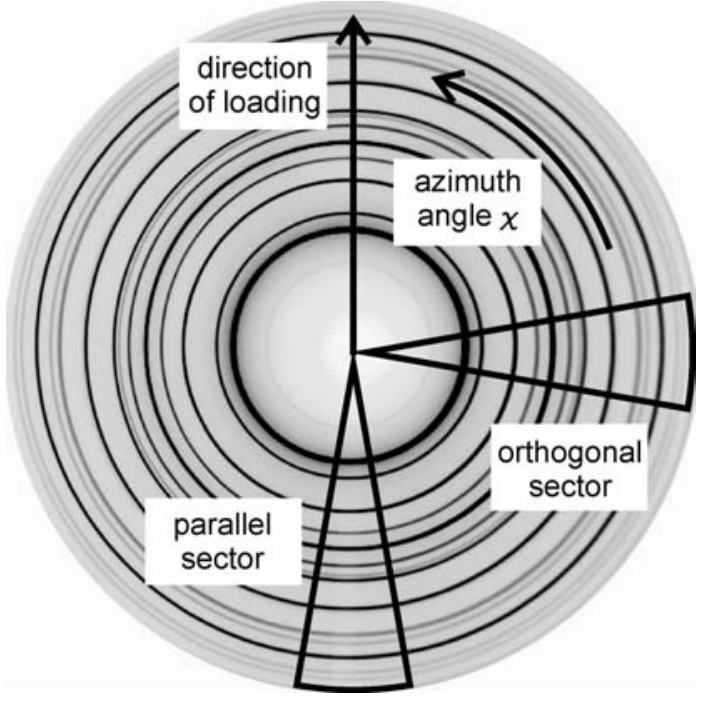

Fig. 2. Two-dimensional X-ray diffraction pattern of the maraging steel PH 13-8 Mo aged at $848 \mathrm{~K}$ for $15 \mathrm{~h}$ in the unloaded state. The scattered intensity is displayed as grayscale, i.e. high intensities are dark and low intensities are bright. The direction of loading is vertical. Markings denote the orthogonal and parallel sectors (opening angle $\pm 10^{\circ}$ ) for azimuthal integration.

ed maraging steel contains only diffraction peaks from the martensitic $\alpha^{\prime}$ phase.

The X-ray diffraction patterns were normalized to the incident intensity of the monochromatic beam and suitably corrected for parasitic background scattering and electronic noise of the detector by using the primary data reduction program FIT2D [46]. All diffraction patterns were azimuthally averaged over $360^{\circ}$ for equal radial distances from the central beam. Additionally narrow sectors $\left( \pm 10^{\circ}\right)$ were integrated parallel and orthogonal to the tensile testing axis (Fig. 2)

\section{Results}

The results of conventional tensile testing of the maraging steel PH 13-8 Mo are illustrated in the engineering stress $\sigma$ versus strain $\varepsilon$ plots in Fig. 3. The strong influence of isothermal aging time at $848 \mathrm{~K}$ on the mechanical properties is clearly visible. In particular, the specific energy of deformation $U$, defined as $U=\int \sigma \mathrm{d} \varepsilon$, the total elongation at

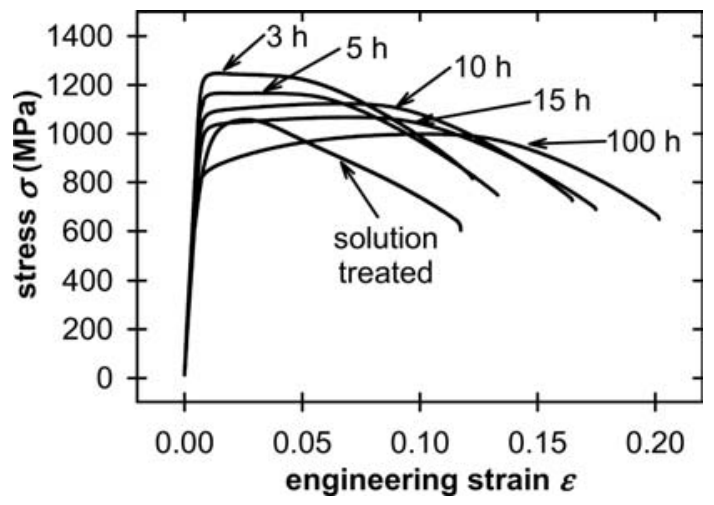

Fig. 3. Engineering stress-strain curves (stress $\sigma$ versus strain $\varepsilon$ ) of the maraging steel PH 13-8 Mo in the solution treated state and aged at $848 \mathrm{~K}$ for different times (see figure). fracture, and the strain hardening increase with aging time. Whereas the yield strength and tensile strength decrease with increasing aging time.

\subsection{In-situ X-ray diffraction performed in tensile testing}

Figure 4 displays a series of azimuthally over $360^{\circ}$ averaged X-ray diffraction patterns of the maraging steel PH 13-8 Mo isothermally aged at $848 \mathrm{~K}$ for $15 \mathrm{~h}$ in various states of the in-situ tensile testing experiment. The intensities of the $\gamma$ phase diffraction peaks strongly decrease with increasing strain $\varepsilon$, whereas the diffraction peaks of the $\alpha^{\prime}$ phase remain mostly unaffected, indicating a strong decline in $\gamma$ phase volume fraction. With increasing $\varepsilon$, the width of the diffraction peaks of both phases increase and a slight shifting of the peak positions is observed. These results are qualitatively found in all aged samples.

For a quantitative analysis of the volume fractions of martensite $V_{\alpha^{\prime}}$ and austenite $V_{\gamma}$, the widely used method of direct comparison of the integrated intensities $I$ was applied. For materials containing only two crystallographic phases, the sum of the volume fractions of the coexisting phases is one. Accordingly, the evaluation follows the procedure described in [35], where it is shown that this method is also valid for textured samples whenever evaluating at least three diffraction peaks of each individual phase. Numerous references confirm the reliability of this evaluation method for analysis of phase fractions in various steels [7, 12, 18, 32, 41]. The volume fraction of austenite $V_{\gamma}$ is given by

$V_{\gamma}=\frac{\frac{1}{N} \sum_{i=1}^{N}\left(\frac{I_{\gamma, i}}{R_{\gamma, i}}\right)}{\frac{1}{N} \sum_{i=1}^{N}\left(\frac{I_{\gamma, i}}{R_{\gamma, i}}\right)+\frac{1}{M} \sum_{i=1}^{M}\left(\frac{I_{\alpha^{\prime}, i}}{R_{\alpha^{\prime}, i}}\right)}$

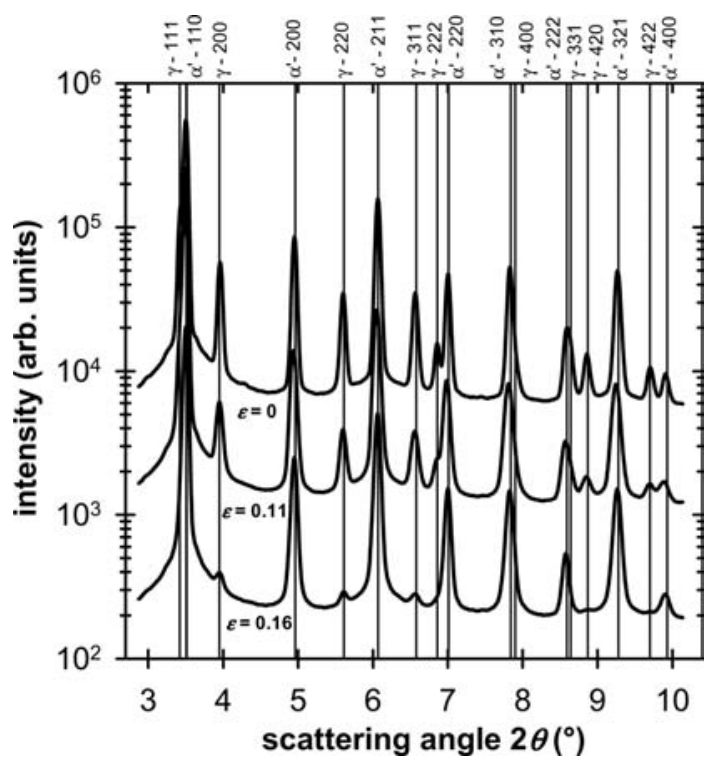

Fig. 4. A typical series of X-ray diffraction patterns (scattering intensity versus scattering angle $2 \theta$ ) during tensile testing of the maraging steel PH 13-8 Mo aged at $848 \mathrm{~K}$ for $15 \mathrm{~h}$. The Miller indices characterize the diffraction peaks. The values given in the figure refer to the strain $\varepsilon$. For the sake of clarity, the curves are shifted vertically by a constant factor with respect to each other.

Int. J. Mat. Res. (formerly Z. Metallkd.) 100 (2009) 11 
where $N$ and $M$ are the total numbers of considered diffraction peaks of the austenite and martensite phase, respectively. The index $i$ refers to the Miller indices $h k l$ of the respective peaks. $R_{\alpha^{\prime}}$ and $R_{\gamma}$ are normalization factors of the diffraction peaks of the $\alpha^{\prime}$ and $\gamma$ phases, respectively, which are given by [35]

$R=|F|^{2} \exp (-2 M) L P A M \frac{1}{v^{2}}$

The factors of the normalization parameter $R$ represented in Eq. (2) were calculated for the in-situ X-ray diffraction experiment using synchrotron radiation with a photon energy of $100 \mathrm{keV}$. For face-centered cubic and body-centered cubic crystal structures, the square of the structure factor $F$ magnitudes are given by $|F|^{2}=4 f^{2}$ and $|F|^{2}=16 f^{2}$, respectively, where $f$ is the atomic scattering factor, taken from reference [47]. The temperature factor (Debye-Waller factor) $\exp (-2 M)$ accounts for the thermal vibration of the crystal lattice. $L$ represents the Lorentz factor, $P$ the polarization factor, $A$ the absorption factor, $M$ the multiplicity of the diffraction peak, and $v$ is the volume of the crystal unit cell. The volume of the crystal unit cell was calculated by $v=a^{3}$, where $a$ is the lattice parameter determined by the scattering angle $2 \theta_{0}$ of the respective diffraction peak. The average lattice parameter of the martensitic $\alpha^{\prime}$ phase and the austenitic $\gamma$ phase were determined from the mean experimental scattering angle $2 \theta_{0}$ of the considered $h k l$ diffraction peaks using Bragg's equation for the cubic lattice (3)

$a=\frac{1}{n} \sum_{i=1}^{n} \frac{\lambda \sqrt{h^{2}+k^{2}+l^{2}}}{2 \sin \theta_{0}}$

where $\lambda$ is the wavelength of the applied radiation and $n$ is the total number of the considered diffraction peaks.

As can be seen in Fig. 4, several diffraction peaks are not clearly divided. Therefore, only the well separated peaks $\alpha^{\prime}$ $200, \alpha^{\prime}-211, \alpha^{\prime}-321, \gamma-200, \gamma-220$, and $\gamma-311$ were taken into account. A pseudo-Voigt distribution [48] was chosen for analysis of the peak profiles. Positions of the diffraction peaks $2 \theta_{0}$, full widths at half peak maximum $w$, peak areas $I$, and coupling parameters $\eta$ were fitted parameters. A linear background was chosen, taking into account the baseline of the diffraction pattern. The X-ray diffraction patterns were analyzed by performing least-squares data fitting of the individual diffraction peaks using a custom-written program based on the free software Python (Python Software Foundation) and Gnuplot (Gnuplot Software by Williams and Kelley). The datasets parallel and orthogonal to the direction of loading and the azimuthally averaged over $360^{\circ}$ were leastsquares fitted by the described model function.

In the unloaded state, the volume fraction of austenite $V_{\gamma}$ in the material aged at $848 \mathrm{~K}$ depends on the aging time and was determined as follows: 7 vol. $\%$ in $3 \mathrm{~h}, 9$ vol. $\%$ in $5 \mathrm{~h}$, 16 vol. $\%$ in $10 \mathrm{~h}, 21$ vol. $\%$ in $15 \mathrm{~h}$, and 30 vol.\% in $100 \mathrm{~h}$. Figure 5 shows the results of the quantitative evaluation of the volume fraction of austenite $V_{\gamma}$ as a function of engineering strain $\varepsilon$ for all five aged samples. It can be seen that $V_{\gamma}$ continuously decreases with increasing strain. The transformation takes place in the elastic as well as the plastic regions, whereas the decrease in the plastic regime is much more pronounced. The fact that not all curves reach the zero line is due to the inability of determining the volume frac-

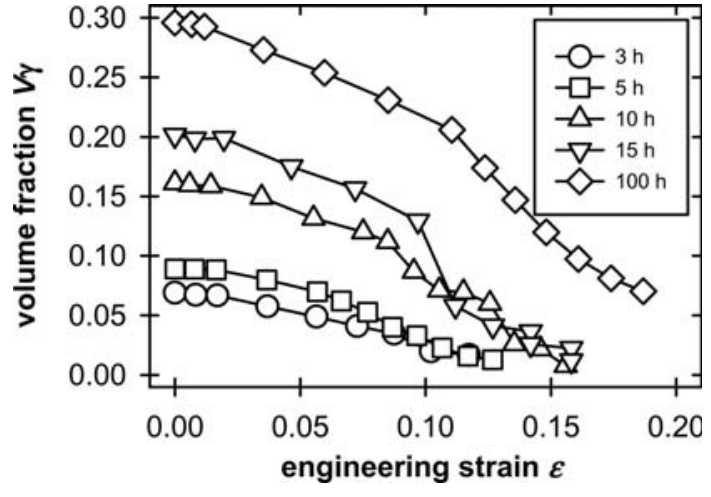

Fig. 5. The volume fraction of austenite $V_{\gamma}$ as a function of engineering strain $\varepsilon$ of the maraging steel PH 13-8 Mo after various aging treatments at $848 \mathrm{~K}$ (see figure legend).

tion of austenite at the onset of fracture. The retained austenite will be transformed between the strain value of the last measurement and elongation at fracture (see Section 3.2.).

As seen in Fig. 4, the width of the diffraction peaks changes with increasing strain. Therefore, the Scherrer size $\Lambda_{h k l}$, also referred to as domain size of the crystallite in the respective crystallographic direction $h k l$, is estimated by applying the Scherrer equation [49]

$\Lambda_{h k l}=\frac{K \lambda}{w_{h k l} \cos \theta_{h k l}}$

where $K$ is a shape-dependent factor, which is set to 0.9 [49], $\lambda$ is the wavelength of the used radiation, $w_{h k l}$ is the full width at half maximum of the diffraction peak, and $2 \theta_{h k l}$ is the corresponding Bragg angle. The term "domain" is attributed to small regions within both the $\alpha^{\prime}$ and the $\gamma$ phases, which have crystallographic order (ordered domains). One single grain may contain several domains of different crystallographic order. Thus the domain size is not equal to the grain size measured by optical microscopy. For the analysis, $w_{h k l}$ from the azimuthally over $360^{\circ}$ integrated X-ray diffraction patterns were taken. The influence of instrumental broadening was checked by measuring a sample of re-crystallized copper, where it was shown that the influence on the width of the diffraction peaks is not significant. Figure 6 shows the results of the domain size $\Lambda$ derived from the $\alpha^{\prime}-200$ (Fig. 6a) and $\gamma$ 200 (Fig. 6b) diffraction peaks as a function of strain. The domain size of both phases decreases with increasing strain in tensile tests, reaching a constant value of about $7 \mathrm{~nm}$ for austenite and martensite. It can be clearly seen that $\Lambda_{\alpha^{\prime}-200}$ and $\Lambda_{\gamma-200}$ of the sample aged at $848 \mathrm{~K}$ for $100 \mathrm{~h}$ are higher than for specimens aged at the same temperature for shorter times. A comparison between martensite and austenite shows that the domain size of martensite decreases more strongly than for austenite for all aging treatments.

The variation in the lattice parameter $a$ in the martensitic $\alpha^{\prime}$ phase and the austenitic $\gamma$ phase as a function of strain $\varepsilon$ is shown in Fig. 7. It is obvious that the lattice parameters parallel and perpendicular to the tensile axis are significantly different. The lattice parameters of martensite and austenite change significantly in the direction parallel to the applied loading in the elastic region and remain fairly constant in the later stages of deformation. The lattice parameters of both phases perpendicular to the direction of external loading do not show considerable changes with increasing strain. 
G. A. Zickler et al.: Transformation of reverted austenite in a maraging steel under external loading
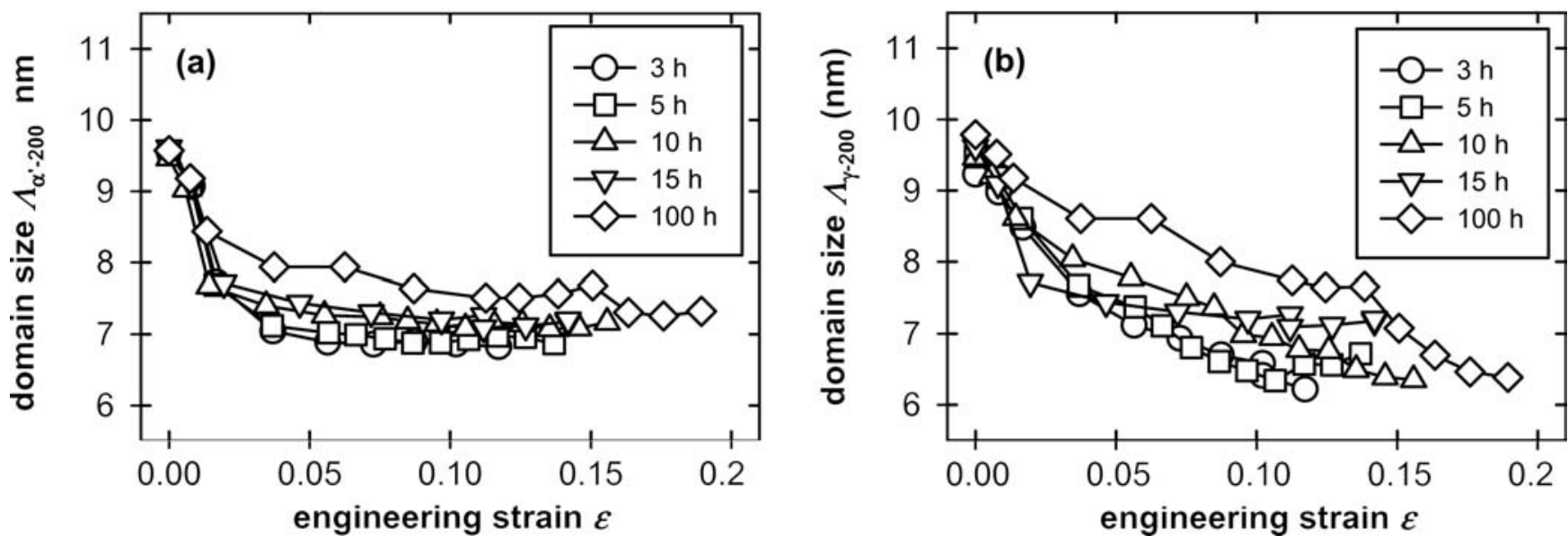

Fig. 6. The variation of the domain size (Scherrer size) $\Lambda$ of the $\alpha^{\prime}-200$ (a) and $\gamma-200$ (b) diffraction peaks as a function of engineering strain $\varepsilon$ of the maraging steel PH 13-8 Mo isothermally aged at $848 \mathrm{~K}$ for various times (see figure legend).

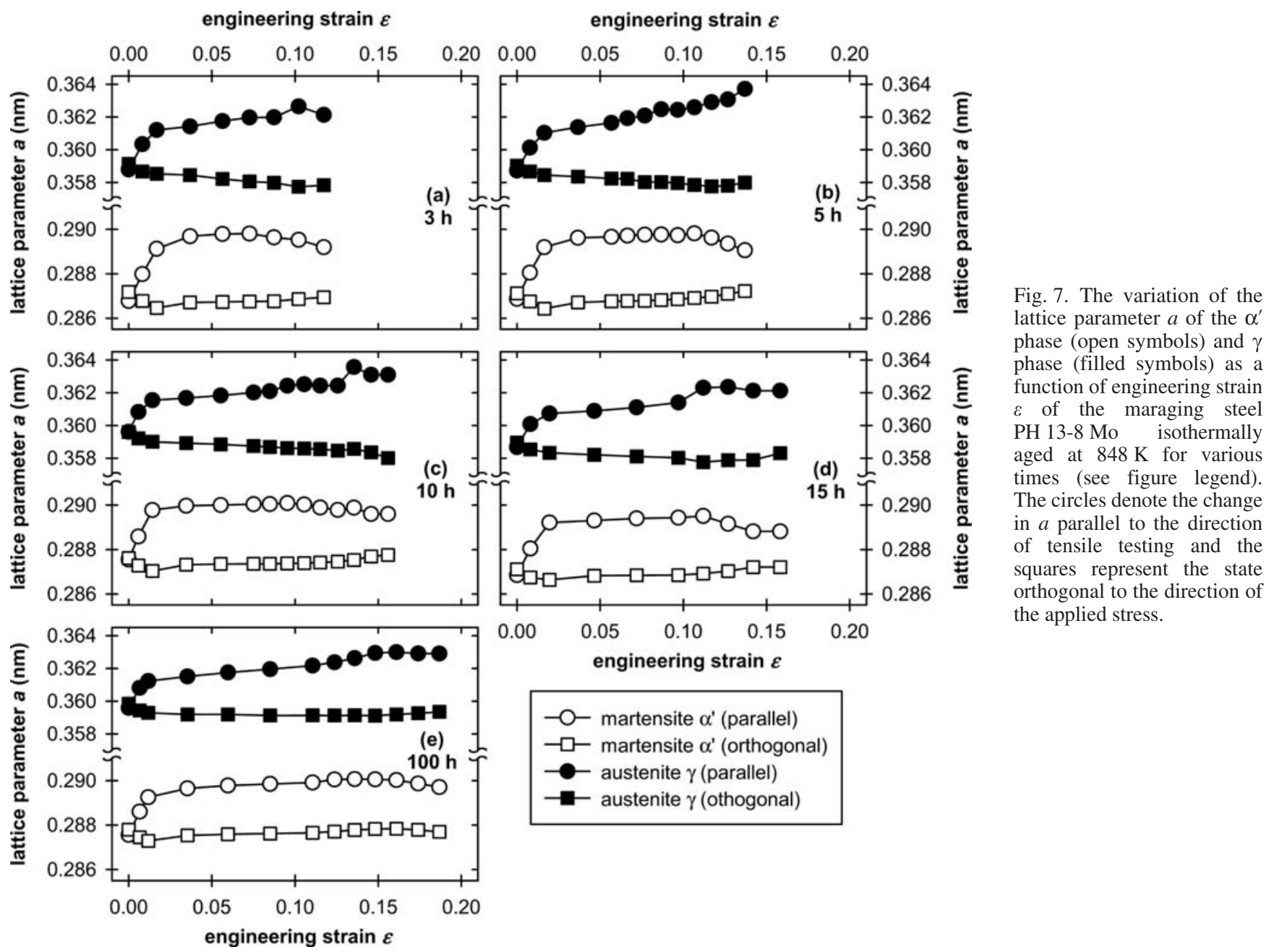

This behavior is qualitatively identical for all five states investigated.

\subsection{Scanning of the specimen after fracture}

After fracture of the samples, one remaining half was scanned along the longitudinal direction with a step width of $1 \mathrm{~mm}$ to show the differences in the transformation behavior between the regions of lateral contraction and uniform elongation. The analysis of the volume fraction of austenite $V_{\gamma}$, the domain size $\Lambda$, and the lattice parameter $a$ were performed according the procedures described in Section 3.1. Figure 8 shows the changes in $V_{\gamma}, \Lambda$, and $a$ of the specimen isothermally aged at $848 \mathrm{~K}$ for $100 \mathrm{~h}$ as functions of the distance from the necking region. The scanning experiment illustrates the significant changes in the respective parameters along the tensile test specimen. The total amount of austenite is transformed in the region close to the fracture surface, 

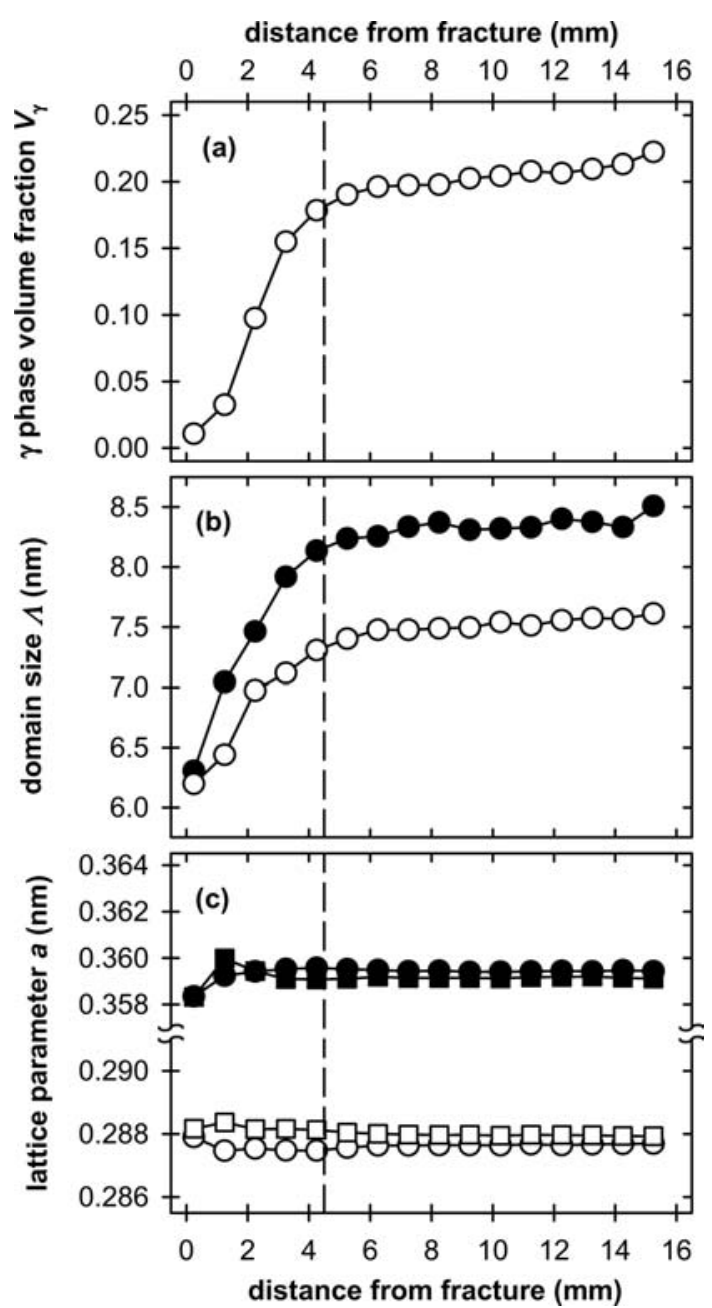

Fig. 8. The variation of (a) the $\gamma$ phase volume fraction $V \gamma$, (b) the domain size $\Lambda$, and (c) the lattice parameter $a$ as functions of distance from the fracture of the maraging steel PH 13-8 isothermally aged at $848 \mathrm{~K}$ for $100 \mathrm{~h}$. The solid symbols in (b) and (c) denote the austenitic $\gamma$ phase $(\gamma-200$ diffraction peak) and the open symbols represent the martensitic $\alpha^{\prime}$ phase ( $\alpha^{\prime}-200$ diffraction peak). In (c) the circles denote the change in the lattice parameter $a$ parallel to the direction of tensile testing and the squares represent the state orthogonal to the direction of applied stress. The dashed line represents the transition from lateral contraction to the zone of uniform elongation.

however, only one third of the initial 30 vol.\% of austenite is transformed in the zone of uniform elongation as illustrated in Fig. 8a. Also the domain size $\Lambda$ shows a strong dependence on the distance from fracture. Figure $8 \mathrm{~b}$ clearly illustrates that $\Lambda$ of both phases becomes smaller in the zone of lateral contraction close to the position of fracture. In the region of uniform elongation, $\Lambda$ of martensite and austenite reaches values of approximately $7.5 \mathrm{~nm}$ and $8.3 \mathrm{~nm}$, respectively. These values are well beyond the initial domain sizes of about $9.5 \mathrm{~nm}$ for both phases prior to tensile testing (Fig. 5). As shown in Fig. 8c, the lattice parameters of austenite and martensite are constant over the investigated scanning length and there are no significant differences between the directions parallel and orthogonal to the applied load.

\section{Discussion}

The martensitic phase transformation of austenite in steels is of great scientific and technological interest due to its in- fluence on the mechanical properties. Up to now, these effects have been intensively studied in austenitic stainless steels and TRIP steels by various methods. However, not much is known about the transformation of reverted austenite under external load in maraging steels. The present work focuses on phase transformation under external loads by applying in-situ X-ray diffraction using high-energy synchrotron radiation.

It is well known that maraging steels exhibit a complex microstructure, containing a martensitic matrix, intermetallic precipitates, and reverted austenite, depending on the heat treatment $[25,26]$. The investigated maraging steel $\mathrm{PH} 13-8$ Mo possesses the intermetallic NiAl phase of ordered body-centered cubic structure (B2 type), which is coherently embedded in the martensitic matrix [27, 28]. Up to now, the formation of reverted austenite in maraging steels has been less investigated. It is reported that the partial dissolution of precipitates during the aging treatment leads to a local enrichment of nickel in the matrix, resulting in a formation of reverted austenite [29, 30]. Therefore, the austenitic phase is free of precipitates and shows a low density of dislocations. As demonstrated in Fig. 4, the X-ray diffraction patterns do not show diffraction peaks of additional phases, e.g. intermetallics, besides martensite and austenite. It is assumed that the scattering intensity of the coherently embedded precipitates is added to the diffraction peaks of the martensitic $\alpha^{\prime}$ phase. Detailed analysis of the shape of the peak profiles does not show any special features, e.g. shoulders adjacent to the peak flanks or the asymmetry of the profiles. Therefore, martensite and precipitates are treated as one crystallographic phase, which is strictly speaking not correct. However, this fact should not affect the main outcomes of the present study.

The influence of the aging time on the volume fraction of austenite $V_{\gamma}$ in the unloaded state and the specific energy of deformation at fracture $U$ are presented in Table 2. An increase in $V_{\gamma}$ and $U$ with increasing aging time is shown. One should keep in mind that $U$ is determined by the sum of the deformation energy of martensite and austenite as well as the energy of the transformation from austenite to martensite. The separation of these different energy parts is not possible on the basis of the present results. Therefore, the increase in $U$ cannot simply be attributed to the increasing $V_{\gamma}$ in the unloaded state. If one thinks about applications, where high energy absorption is required, heat treatments which result in a higher value of $U$ could be very beneficial.

Table 2. The influence of the heat treatment on the volume fraction of austenite $V_{\gamma}$ in the unloaded state and the specific energy of deformation at fracture $U$ of the maraging steel PH 13-8 Mo.

\begin{tabular}{|c|c|c|}
\hline heat treatment & $\begin{array}{c}\text { volume fraction of } \\
\text { austenite } V_{\gamma} \\
\text { in unloaded state }\end{array}$ & $\begin{array}{c}\text { specific energy } \\
\text { of deformation } \\
\text { at fracture } \\
U\left(\mathrm{MJ} \mathrm{m}^{-3}\right)\end{array}$ \\
\hline solution treated & 0 & 119 \\
aged at $848 \mathrm{~K}, 3 \mathrm{~h}$ & 0.07 & 130 \\
aged at $848 \mathrm{~K}, 5 \mathrm{~h}$ & 0.09 & 136 \\
aged at $848 \mathrm{~K}, 10 \mathrm{~h}$ & 0.16 & 152 \\
aged at $848 \mathrm{~K}, 15 \mathrm{~h}$ & 0.21 & 154 \\
aged at $848 \mathrm{~K}, 100 \mathrm{~h}$ & 0.30 & 169 \\
\hline
\end{tabular}


The decrease in the domain size $\Lambda$ can be interpreted as an increasing dislocation density in the material. As shown in Fig. 6, the rate of decrease is higher for the martensitic $\alpha^{\prime}$ phase than for the austenitic $\gamma$ phase. However, the total decrease of $\Lambda$ is higher for the austenitic phase, which is due to the lower dislocation density in the austenite in the unloaded state before tensile testing. Thus, strain hardening is much higher in the austenitic phase than in the martensitic phase, which can also be seen in the tensile testing curves (Fig. 3). The constant level of $\Lambda$ at higher strain might be due to constant density of dislocations and equilibrium between strengthening and softening.

There is no significant change in the lattice parameters orthogonal to the direction of tensile testing for both phases as function of strain (Fig. 7). If there were differences in the chemical composition of the austenitic grains, one would expect preferred transformation of grains containing less austenite stabilizing elements in the early stages of deformation. This effect would result in a peak shift with proceeding transformation. However, the present results indicate that there are no peak shifts and therefore no chemical variations of specific elements between single austenite grains.

Katz et al. [32] reported two types of austenite in plastically deformed maraging steels, one mechanically stable and the other unstable. The material investigated in the present work does not show the same behavior. The scanning of the sample after fracture (Fig. 8) clearly demonstrates that the entire amount of austenite transforms to martensite in the zone of lateral contraction. This discrepancy is most probably due to the high amounts of nickel and cobalt and the absence of chromium in the material investigated by Katz et al., which leads to an additional stabilization of the austenite.

A stepwise transformation behavior of strain-induced martensitic transformation, as reported by Hedström et al. [43] for an austenitic stainless steel, could not be observed for the investigated maraging steel. However, one should keep in mind the more advanced experimental setup and the higher resolution in strain of the investigations by Hedström et al. [43]. Therefore, the stepwise transformation cannot be excluded in the maraging steel under investigation.

\section{Summary}

The martensitic phase transformation of reverted austenite in the maraging steel PH 13-8 Mo under external load was studied in-situ by X-ray diffraction using high-energy synchrotron radiation. The volume fraction of austenite, the domain size of the crystallites, so-called Scherrer size, and the crystal lattice parameter were studied as functions of strain for six differently heat treated specimens. The results are summarized as follows:

(a) Aging at $848 \mathrm{~K}$ strongly influences the mechanical properties of the investigated maraging steel. The specific energy of deformation at fracture, the elongation at fracture, and the strain hardening increase with increasing aging time.

(b) The solution treated material does not contain austenite, however, the aging treatment increases the volume fraction of reverted austenite up to $30 \%$. The reverted austenite in the maraging steel is not mechanically stable and transforms to martensite under external load. The aged samples show martensitic transformations of nearly the entire amount of austenite during tensile testing.

(c) Scanning of the sample in the longitudinal direction shows that the volume fraction of austenite and the domain sizes strongly depend on the distance from the point of fracture. The volume fraction decreases towards zero in the zone of lateral contraction, whereas only one third of the austenite is transformed in the region of uniform elongation.

(d) In conclusion, X-ray diffraction using high-energy synchrotron radiation in combination with a special in-situ tensile testing machine is a powerful experimental tool, which procures deeper insight into the martensitic phase transformation in maraging steels. However, additional investigations by applying atom probe tomography, electron microscopy, and mechanical testing should be performed to study the transformation of reverted austenite in maraging steels, which is currently work in progress.

The authors thank T. Dose, T. Fischer, and R. Kirchhof for providing assistance at the GKSS Engineering Materials Science Beamline HARWI-II, Hamburg, Germany. Financial support from the Deutsches Elektronen-Synchrotron (DESY) and the European Community (reimbursement contract RII3-CT-2004-506008 (IA-SFS)) is gratefully acknowledged.

\section{References}

[1] E. Scheil: Z. anorg. allg. Chem. 207 (1932) 21. DOI: $10.1002 /$ zaac. 19322070103

[2] T. Angel: J. Iron Steel Inst. 177 (1954) 165.

[3] D.C. Ludwigson, J.A. Berger: J. Iron Steel Inst. 207 (1969) 63.

[4] G.B. Olson, M. Cohen: Metall. Trans. A 6 (1975) 791. DOI:10.1007/BF02672301

[5] A. Sato, Y. Sunaga, T. Mori: Acta Metall. 25 (1977) 627. DOI:10.1016/0001-6160(77)90004-9

[6] A. Sato, M. Kato, Y. Sunaga, T. Miyazaki, T. Mori: Acta Metall. 28 (1980) 367. DOI:10.1016/0001-6160(80)90171-6

[7] J. Talonen, P. Aspegren, H. Hänninen: Mater. Sci. Tech. 20 (2004) 1506. DOI: $10.1179 / 026708304 X 4367$

[8] M. Onyuna, H. Oettel, U. Martin, A. Weiß: Adv. Eng. Mater. 6 (2004) 529. DOI:10.1002/adem.200400411

[9] E. Nagy, V. Mertinger, F. Tranta, J. Sólyom: Mater. Sci. Eng. A 378 (2004) 308. DOI:10.1016/j.msea.2003.11.074

[10] H.S. Wang, J.R. Yang, H.K.D.H. Bhadeshia: Mater. Sci. Tech. 21 (2005) 1323. DOI:10.1179/174328405X63980

[11] H. Oettel, U. Martin: Int. J. Mat. Res. (formerly Z. Metallkd.) 97 (2006) 1642.

[12] A.K. De, J.G. Speer, D.K. Matlock, D.C. Murdock, M.C. Mataya, R.J. Comstock Jr.: Metall. Mater. Trans. A 37 (2006) 1875. DOI:10.1007/s11661-006-0130-y

[13] V. Mertinger, E. Nagy, F. Tranta, J. Sólyom: Mater. Sci. Eng. A $481-482$ (2008) 718 .

[14] V.F Zackay, E.R. Parker, D. Fahr, R. Busch: ASM Trans. Q. 60 (1967) 252.

[15] O. Matsumura, Y. Sakuma, H. Takechi: Scripta Metall. 21 (1987) 1301. DOI:10.1016/0036-9748(87)90103-7

[16] A. Itami, M. Takahashi, K. Ushioda: ISIJ Int. 35 (1995) 1121. DOI:10.2355/isijinternational.35.1121

[17] E. Girault, A. Mertens, P. Jacques, Y. Houbaert, B. Verlinden, J. van Humbeeck: Scripta Mater. 44 (2001) 885. DOI: $10.1016 / S 1359-6462(00) 00697-7$

[18] S. Kruijver, L. Zhao, J. Sietsma, E. Offerman, N. van Dijk, L. Margulies, E. Lauridsen, S. Grigull, H. Poulsen, S. van der Zwaag: Steel Res. 73 (2002) 236.

[19] S. van der Zwaag, L. Zhao, S.O. Kruijver, J. Sietsma: ISIJ Int. 42 (2002) 1565. DOI:10.2355/isijinternational.42.1565

[20] K. Hase, C. Garcia-Mateo, H.K.D.H. Bhadeshia: Mater. Sci. Tech. 20 (2004) 1499. DOI:10.1179/026708304X6130

[21] P.J. Jacques: Curr. Opin. Solid State Mater. Sci. 8 (2004) 259. DOI:10.1016/j.cossms.2004.09.006

Int. J. Mat. Res. (formerly Z. Metallkd.) 100 (2009) 11 
[22] P.J. Jacques, Q. Furnémont, F. Lani, T. Pardoen, F. Delannay: Acta Mater. 55 (2007) 3681. DOI:10.1016/j.actamat.2007.02.029

[23] D. Liu, F. Fazeli, M. Militzer, W.J. Poole: Metall. Mater. Trans. A 38 (2007) 894. DOI:10.1007/s11661-007-9116-7

[24] S. Zaefferer, J. Ohlert, W. Bleck: Acta Mater. 52 (2004) 2765 DOI:10.1016/j.actamat.2004.02.044

[25] R.F. Decker, S. Floreen, in: R.K. Wilson (Ed.), Maraging Steels: Recent Developments and Applications, The Minerals, Metals \& Materials Society, Warrendale (PA) (1988) 1.

[26] W. Sha, A. Cerezo, G.D.W. Smith: Metall. Trans. A 24 (1993) 1221. DOI: $10.1007 / \mathrm{BF} 02668190$

[27] J.-M. Cloué, B. Viguier, E. Andrieu: Metall. Mater. Trans. A 36 (2005) 2633. DOI:10.1007/s11661-005-0261-6

[28] D.H. Ping, M. Ohnuma, Y. Hirakawa, Y. Kadoya, K. Hono: Mater. Sci. Eng. A 394 (2005) 285. DOI:10.1016/j.msea.2004.12.002

[29] X. Li, Z. Yin: Mater. Lett. 24 (1995) 239. DOI: $10.1016 / 0167-577 X(95) 00109-3$

[30] U.K. Viswanathan, G.K. Dey, V. Sethumadhavan: Mater. Sci. Eng. A 398 (2005) 367. DOI:10.1016/j.msea.2005.03.074

[31] H. Nakagawa, T. Miyazaki: J. Mater. Sci. 34 (1999) 3901. DOI:10.1023/A:1004626907367

[32] Y. Katz, H. Mathias, S. Nadiv: Metall. Trans. A 14 (1983) 801. DOI: $10.1007 / \mathrm{BF} 02644283$

[33] D.H. Sherman, S.M. Cross, S. Kim, F. Grandjean, G.J. Long, M.K. Miller: Metall. Mater. Trans A 38 (2007) 1698. DOI: $10.1007 / \mathrm{s} 11661-007-9160-3$

[34] M.J. van Genderen, M. Isac, A. Böttger, E.J. Mittemeijer: Metall Mater. Trans. A 28 (1997) 545. DOI:10.1007/s11661-997-0042-5

[35] M.J. Dickson: J. Appl. Cryst. 2 (1969) 176. DOI:10.1107/S0021889869006881

[36] Y.V. Taran, M.R. Daymond, D. Eifler, J. Schreiber: Appl. Phys. A 74 (2002) S 1391.

[37] K.-D. Liss, A. Bartels, A. Schreyer, H. Clemens: Texture Microstruct. 35 (2003) 219. DOI:10.1080/07303300310001634952

[38] S.E. Offerman, N.H. van Dijk, J. Sietsma, S. Grigull, E.M. Lauridsen, L. Margulies, H.F. Poulsen, M.T. Rekveldt, S. van der Zwaag: Science 298 (2002) 1003. PMid:12411699; DOI:10.1126/science.1076681

[39] A. Pyzalla, B. Camin, T. Buslaps, M. Di Michiel, H. Kaminski, A. Kottar, A. Pernack, W. Reimers: Science 308 (2005) 92. PMid:15802600; DOI:10.1126/science.1106778

[40] S.D. Choi, H.S. Kim, J.H. He, S.H. Park: J. Mater. Sci. Lett. 21 (2002) 353. DOI:10.1023/A:1014990714332

[41] N.H. van Dijk, A.M. Butt, L. Zhao, J. Sietsma, S.E. Offerman, J.P. Wright, S. van der Zwaag: Acta Mater. 53 (2005) 5439. DOI:10.1016/j.actamat.2005.08.017

[42] E. Jimenez-Melero, N.H. van Dijk, L. Zhao, J. Sietsma, S.E. Offerman, J.P. Wright, S. van der Zwaag: Acta Mater. 55 (2007) 6713 DOI:10.1016/j.actamat.2007.08.040

[43] P. Hedström, U. Lienert, J. Almer, M. Odén: Scripta Mater. 56 (2007) 213. DOI:10.1016/j.scriptamat.2006.10.009
[44] P. Hedström, U. Lienert, J. Almer， M. Odén: Mater. Lett. 62 (2008) 338. DOI:10.1016/j.matlet.2007.05.054

[45] T. Lippmann, L. Lottermoser, F. Beckmann, R.V. Martins, T. Dose, R. Kirchhof, A. Schreyer, in: W. Caliebe, W. Drube, K. Rickers, J.R Schneider (Eds.) HASYLAB Annual Report, HASYLAB/DESY, Hamburg (2007) 113.

[46] A.P. Hammersley, S.O. Svensson, M. Hanfland, A.N. Fitch, D. Häuserman: High Press. Res. 14 (1996) 235. DOI: $10.1080 / 08957959608201408$

[47] J.A. Ibers, W.C. Hamilton (Eds.): International Tables for X-ray Crystallography, Vol. IV, Kynoch Press, Birmingham, (1974).

[48] T.H. de Keijser, E.J. Mittemeijer, H.C.F. Rozendaal: J. Appl. Cryst. 16 (1983) 309. DOI:10.1107/S0021889883010493

[49] J.I. Langford, A.J.C. Wilson: J. Appl. Cryst. 11 (1978) 102. DOI: $10.1107 / \mathrm{S} 0021889878012844$

(Received June 24, 2008; accepted February 25, 2009)

\section{Bibliography}

DOI 10.3139/146.110219

Int. J. Mat. Res. (formerly Z. Metallkd.)

100 (2009) 11; page 1566-1573

(C) Carl Hanser Verlag GmbH \& Co. KG

ISSN $1862-5282$

\section{Correspondence address}

Gerald A. Zickler

Christian Doppler Laboratory for Early Stages of Precipitation

Department of Physical Metallurgy and Materials Testing

Montanuniversität Leoben

Franz-Josef-Straße 18, A-8700 Leoben, Austria

Tel.: +4338424024206

Fax: +4338424024202

E-mail: gerald.zickler@mu-leoben.at

You will find the article and additional material by entering the document number MK110219 on our website at www.ijmr.de 